\title{
Mobile positioning in sustainability studies: the social positioning method in studying commuter's activity spaces in Tallinn
}

\author{
R. Ahas ${ }^{1}$, Ü. Mark ${ }^{2}$, O. Järv ${ }^{1} \&$ M. Nuga ${ }^{1}$ \\ ${ }^{1}$ Institute of Geography, University of Tartu, Tartu, Estonia \\ ${ }^{2}$ Positium ICT, Niine 11, Tallinn, Estonia
}

\begin{abstract}
We introduce the mobile phone positioning-based social positioning method in studying activity spaces of commuters and residents of the city centre in Tallinn. The social positioning method (SPM) studies space-time behaviour by analysing the location coordinates of mobile phones and the social characteristics of the people carrying them. Our study experiments took place in the Tallinn and Tartu region in Estonia from 2003-2006. The results demonstrate that mobile positioning-based tracing is applicable in geographical studies, as an analysis of temporal movement patterns and activity spaces. This is good reference for analysing travel diaries, especially for analysing daily activity spaces and space consumption which is a key issue in sustainable planning of the sprawling cities. The biggest advantage of mobile positioning-based methods is that mobile phones are wide-spread, positioning works inside buildings, and the collection of movement data is done by a third party at regular intervals. The disadvantage of mobile positioning today is relatively low preciseness and surveillance fears. The boom in the generation of phones with A-GPS will raise positioning accuracy in the near future.
\end{abstract}

Keywords: mobile positioning, commuters' activity spaces, social positioning method, sustainable city, Tallinn, Estonia.

\section{Introduction}

Urban sprawl, extensive space consumption and rising traffic demands are major problems in both western and eastern cities. This has been one of the major issues in urban planning during the last 30 years. Concepts of sustainable 
planning and smart growth are aimed at designing energy- and time-effective settlements and transportation models, which need input data from space-time movement analyses and models [1]. During the last decades, geographers have evolved different methods to gather and analyse the space-time movement data of society and individuals [2]. In the current paper we introduce the results of pilot studies using the positioning data of personal mobile phones for researching human space-time behaviour in the Tallinn urban region. This method is called the social positioning method (SPM) [3] and it describes an individuals' movement patterns using the positioning co-ordinates of their personal communication devices combined with the owners' personal/social attributes. This new data has some advantages in urban studies; better information can help to plan environmentally, socially and economically balanced cities. The biggest advantage of mobile positioning data is that phones are widespread and they can be used as terminals to get a spatial response from the public. The biggest problem with mobile positioning data is surveillance fear and privacy issues, as mobile phones are very personal.

\section{Data and study area}

\subsection{Tallinn}

The study area - the capital of Estonia Tallinn - can be characterised today by its fast development and sprawling urban environment. The area of the capital of Estonia, Tallinn, is $158 \mathrm{~km}^{2}$, with a population of 400000 . The largest residential areas in Tallinn are Lasnamäe, Mustamäe and Õismäe, which consist of apartment buildings built between the 1960s and 1990. A significant part of the population is also located within the city centre - 44778 inhabitants in 2005. The compact medieval old town in the centre of Tallinn is in UNESCO's world cultural heritage list. The area of urban agglomeration around Tallinn extends as far as $50-70 \mathrm{~km}$ from the core city [4,5]. In suburban areas, new residential areas and shopping centres have been extensively developed. Our field works showed that majority of new settlement areas locate still in the closest neighbourhood of city (Figure 1). The population of the entire urban region of Tallinn is 550000 inhabitants. A large number of inhabitants commute daily to work using mainly automobile transportation. It is comprehensible that the relatively good and cheap system of public transportation from soviet times does not suit anymore. During the last 15 years the number of cars has almost doubled, reaching 319 cars per 1000 inhabitants in Tallinn in 2004. In 1990 people made 603 million journeys and in 2004 only 213 million journeys using public transportation [6].

\subsection{Mobile positioning data}

The collection and analysis of the social positioning data was conducted by the Estonian company Positium ICT [7], which is currently developing SPM applications in co-operation with the Institute of Geography, University of Tartu. 


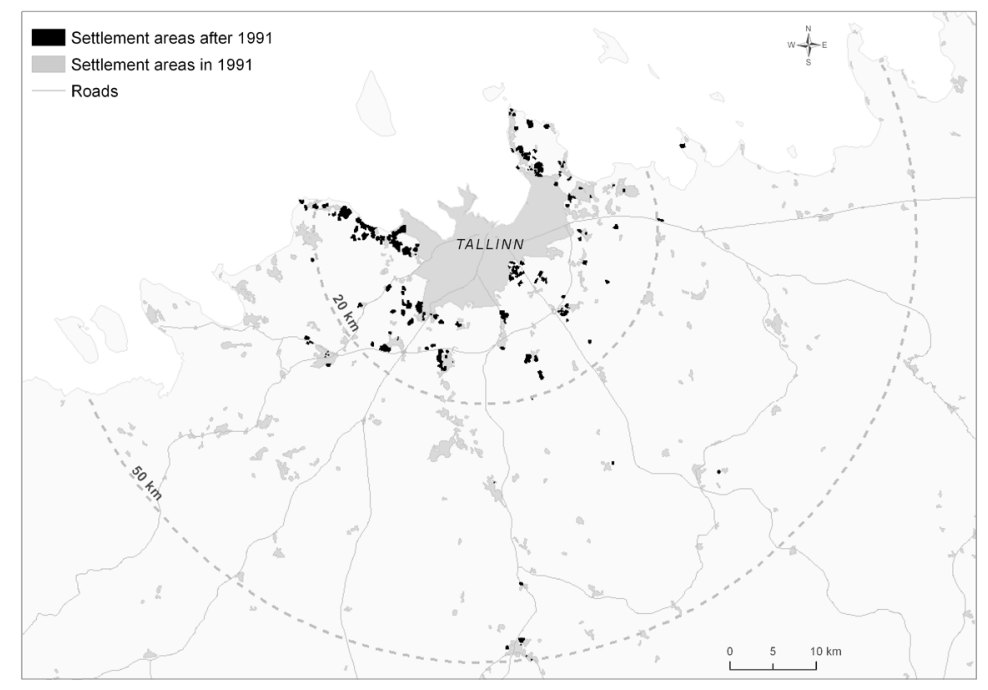

Figure 1: New settlement areas in urban region of Tallinn $(1.01 .2006,5$ or more houses/apartments in range of $200 \mathrm{~m}$ ).

In the pilot studies, the EMT network, Estonia's biggest operator, was used. EMT has technical and organisational capabilities for location-based services using the CGI+TA method.

Movements of a sample of 117 individuals were recorded by positioning their personal mobile phones in Tallinn in 2004. The experimental sample of the first study in 2004 was proportionally divided into two groups: a) 91 residents of the central part of the city; b) 26 commuters living outside the city limits. The locations of the selected phones were registered every 30 minutes between 7 am and $11 \mathrm{pm}$ during the period from February 18-22, 2004. During the 5 days the motion of the 117 participants was observed and altogether more than 14000 location coordinates were registered. In addition to the mobile positioning data, each individual completed a personal questionnaire describing social characteristics and travel behaviour.

The calculations of positioning error on network characteristics showed that in urban areas the accuracy of $61 \%$ of positioning cases remained within 1000 metres and within 3000 metres for $53 \%$ of positioning cases in rural areas of Estonia. Accuracy checks conducted with GPS indicated that the error is less than 1200 metres in $99 \%$ of positioning cases in urban areas.

Additionally, to understand the suburbanisation, structured interviews were held with 13 commuters, who were asked to answer some questions about their space-time movement and life style. The respondents consisted of 1 with basic and 1 with secondary education; 4 trade school education and 7 persons with higher education. The dominant group consisted of married people with children, one was single and two persons were in common-law marriages. 


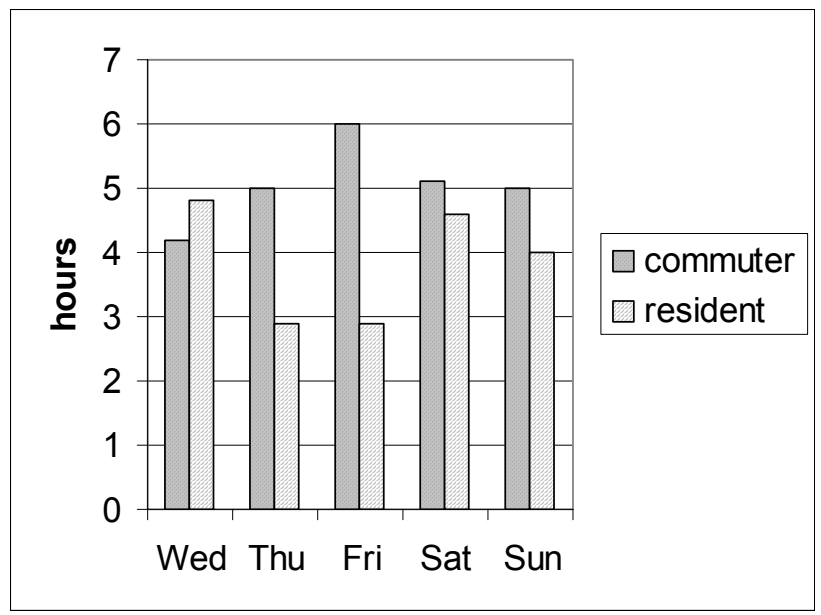

Figure 2: Mean time spent in "other" locations (filter $2 \mathrm{~km}$ in suburbs and $500 \mathrm{~m}$ in city centre) than home or work between 7:00 and 23:00.

\section{Mobile positioning data in urban studies}

\subsection{Space-time behaviour and activity spaces}

The social positioning method allows us to trace the movement of people with relatively good spatio-temporal precision. This data helps us to analyse personal activity spaces, which has a great field of applications in urban studies and planning. We used the pilot study in Tallinn to compare the activity spaces of commuters and residents of the city centre. The main differences between commuters and residents of the city centre are in the use of urban space and the temporal rhythm of daily movement: commuters start their day earlier and spend less time on "other" locations besides home and work anchor points (Figure 2). Compared to the average commuter, who covered $55 \mathrm{~km} /$ day during the experiment period, the average resident covered only $31 \mathrm{~km}$ per day (Figure 3 ). The analysis of all the positioning events made during 5 days shows that during 30 min periods the resident moves on average $2266 \mathrm{~m}$, but the commuter, 4426 $\mathrm{m}$. This shows differences in the lifestyles and ecological footprints of people working in the same area, even in the same office. These people differ also in their utilisation of other resources, which could be further estimated on the basis of the given movement data. According to the estimations of the latest studies, suburbanisation and urban sprawl are still rapidly growing trends in Tallinn, and transportation problems should be linked to their sources - the sprawling communities and persons living there. Our interviews showed that most of people who moved into suburban regions wanted to live closer to nature. SPM analysis can be one way to estimate and calculate personal energy consumption and ecological footprint [8]. 


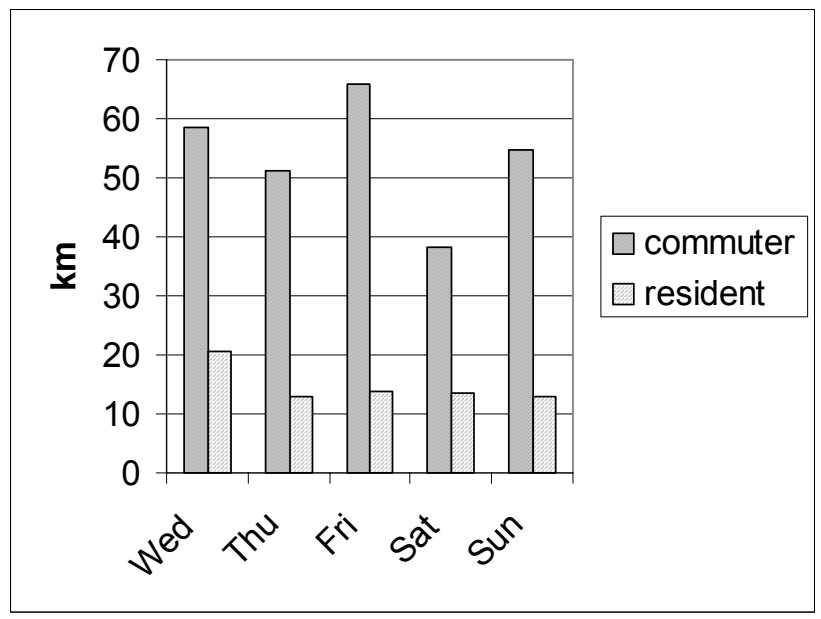

Figure 3: Mean daily movement of commuters and city centre residents in Tallinn during SPM experiment (February 2004).

Another parameter describing the movement and lifestyle of commuters is the distance from the city centre. For this reference point we used the Town Hall Square in the Old Town of Tallinn. The distance from the centre characterizes the life style of sybarites, the spatial distribution of functions in the city. Figure 4 shows mean distances from the city centre for the 26 commuters $(5-35 \mathrm{~km})$ compared to the 91 residents of the city centre $(2-20 \mathrm{~km})$. The differences in space utilisation are obvious: the residents live in the centre and they move in various neighbourhoods (work, service, free time); the commuters live quite far in the suburbs, work near the centre of the city and use other services on the way home. The interviews also showed that commuters used services not situated by the road home only in rare cases of specific need. It is essential to stress that all the commuters taking part in this experiment were working in the centre of town. Taking into consideration the whole urban region, the concentration of commuters in the city centre is not so great. On the weekend, residents and commuters both travel away from the city and come back on Sunday afternoon.

\subsection{Space consumption and social features}

Extensive space consumption and urban sprawl are related to the lifestyle of city residents. To improve planning and administration it is important to understand the lifestyle, social characteristics and other determinants of space consumption. SPM data allows studying the features of respondents. We studied correlations between some personal features and the length of daily movement of 117 people positioned in Tallinn. The target group had 26 commuters - dominated by a well-educated and successful middle class who lived in suburbs behind the administrative borders of Tallinn and mostly worked in the centre of the city. We compared their space-time movement with educated and successful residents of 
the city centre. The commuters have chosen their place of residence mainly in last 10 years. The educated and successful residents of the city centre are the group most at risk to become commuters in the near future.

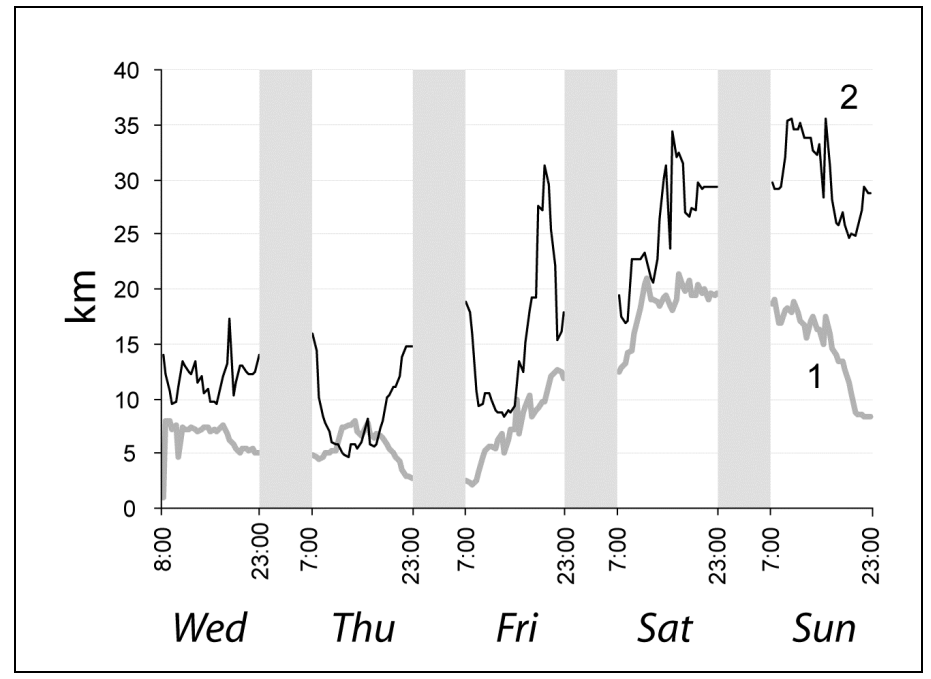

Figure 4: The average distance from the Town Hall Square in Tallinn. 1. 91 city centre residents; 2 . 26 commuters.

The results show that the amount of movement depends on the place of residence and some personal features. Although the sample was unequal we can make some inferences about the factors affecting the length of journeys. As a whole there is a significant correlation between movement sums and location of home. The age of the respondents had a significant influence on movement only on Saturdays, where children (0-19) move only 3,7 km, older people (over 40) $29,8 \mathrm{~km}$ and young people (20-39) $42,7 \mathrm{~km}$. Education has a significant influence only on weekends, where less educated persons and children moved only 3,1-8,5 km; persons with higher education 32,1-37 km and persons with secondary education $41,2-45,7 \mathrm{~km}$. On workdays the link between the length of distance and transportation preference (car, public, walking-bicycle) of the respondents has a significant correlation. Other features like gender, occupation, income and family status do not have significant correlations. Similar results were also drawn out by method of confidence ellipses of activity spaces [9]. This method gave us some extra information and significance measures (Table 1).

Interviews showed that many of the commuters presumed that they live an untypical life and that their offbeat system is hard to put into the frames of a scientific study. Opinions such as this were given, for example, by the director of big company who had a flexible work schedule with no daily routine and a freelance yoga trainer. Nevertheless the positioning data showed that most of 
these unusual commuters still go to work every day quite early in the morning and get home late and have relatively similar (routine) space consumption during workdays.

Table 1: $\quad$ Significance of social characteristics of the studied 117 participants on activity-space ellipse parameters by the results of the KruskalWallis test $(* *-\mathrm{p}<0,01 ; *-\mathrm{p}<0,05)$.

\begin{tabular}{l|c|c|c|c}
\hline & $\begin{array}{c}\text { Major } \\
\text { axis }\end{array}$ & $\begin{array}{c}\text { Minor } \\
\text { axis }\end{array}$ & Angle & Area \\
\hline Region & Yes** & Yes** & - & Yes** \\
Age & - & Yes & - & - \\
Gender & - & - & - & - \\
Occupation & Yes* & - & - & Yes \\
Education & Yes* & Yes* & - & Yes* \\
Marital status & - & - & - & - \\
Children & - & - & Yes & - \\
Pay & - & - & - & - \\
Resident/commuter & Yes** & Yes** & - & Yes** \\
\hline
\end{tabular}

Commuters usually do not spend their free time in town. The cinema and theatre are visited two or three times a year; most of the interviewed people said that there was not enough time to take part in the culture events in the city. Also it was easier to participate in sports closer to home or to enjoy the local nature. Commuters spend weekends and holidays mostly at home, in $10-20 \%$ of cases they travel abroad or to other parts of Estonia. Outside of the working day, the commuters visit the centre of Tallinn or Old town less than once a month to take part in festive occasions or dine in fine restaurants. Commuters believed that when they were living in town they visited the old town more often. For the commuters the distance from culture and the city centre was a critical drawback. Residents of city centre are still often visitors of the Old town. They visit mostly restaurants, bars and cultural events. Other services such as shopping or banking are less related with the Old town and city centre.

\section{Conclusions}

Space-time movement data is an important source for urban studies and for developing sustainable planning models. For sustainable planning practices it is necessary to have very detailed movement outlines, but our experiences with 3 SPM studies show that there is also a need for very detailed data of personal characteristics from questionnaires and travel diaries, as lifestyle is a main driving force behind growing suburbanisation and traffic demand. Institute of Geography, University of Tartu has developed SPM based ecological footprint tracker for educational purposes. If people can compare own space and energy consumption with others in society this can be used for rising environmental awareness and for regulating sprawl with soft measures. 
The main objective of our pilot study - to test the SPM method- showed that the social positioning method allows recording and analysis of personal activity spaces in more detail than earlier as mobile positioning data has an additional quantitative data layer to traditional questionnaires and travel diaries. This quantitative layer helps us to measure actual movements, link it with space and energy consumption and to control hypothesis from qualitative research. The preciseness of mobile positioning is improving rapidly. In 2006 A-GPS will start working in Estonia and in some other European countries, which will permit positioning data with an accuracy of a few meters.

The analysis of the movements of 117 persons showed that even if our sample was small and unbalanced we got comparative measurements of the movements of commuters and city centre residents. Commuters travelled $50-70 \mathrm{~km}$ and residents of the city centre only $10-20 \mathrm{~km}$ daily. Dispersed suburban communities of commuters create traffic demands as public transportation and public services are not well developed in new dwelling areas. Commuters have less free time and they spend less free time in city centre. Spatial movement has a significant correlation with age, education level and the transportation preference of respondents, as these are the main characteristics typical for commuters. The main question to be addressed considering the sustainability of the urban region of Tallinn is planning new suburbs near existing transportation networks and existing social infrastructures.

\section{Acknowledgements}

The authors wish to thank the Department of Planning of Tallinn, EMT Ltd., Positium ICT. and all respondents. This project was partly funded by the Target Funding Project No. 0182143s02 of the Ministry of Education and Science, Estonia.

\section{References}

[1] Timmermans, H., Arentze T. \& Joh, C.-H., Analysing space-time behaviour: new approaches to old problems. Progress in Human Geography, 26, pp 175-190, 2002.

[2] Handy, S., Smart growth and the transportation - Land use connection: What does the research tell us? International Regional Science Review, 28, pp 146-167, 2005.

[3] Ahas, R. \& Mark, Ü., Location based services - new challenges for planning and public administration? Futures, 37, pp 547-561, 2005.

[4] Tammaru, T., Kulu, H. \& Kask, I., Urbanization, suburbanization, and counterurbanization in Estonia. Eurasian geography and economics, 45, pp 212-229, 2004.

[5] Ahas, R. \& Leetmaa, K., Suburbanisation and commuting in Tallinn. Estonian Architectural Review, 45(3), pp 16-21, 2005.

[6] Statistical office of Estonia, Website and databases, www.stat.ee, Last visit 20.01.2006. 
[7] Positium, Website of Positium ICT, www.positium.com, last visit 12.03.2006.

[8] Muniz, I. \& Galindo, A., Urban form and the ecological footprint of commuting. The case of Barcelona. Ecological Economics, 55, pp 499514, 2005.

[9] Schönfelder, S. \& Axhausen, K.W., Activity spaces: Measures of social exclusion? Transport Policy, 10, pp 273-286, 2003. 